\title{
Effects of sitagliptin on blood glucose, lipids, pancreatic $\beta$ cell secretory function and insulin resistance in patients with type 2 diabetes mellitus
}

\author{
Song Wenrong ${ }^{1}$, Zhang Lei ${ }^{2}$, Pan Zaoxia ${ }^{3}$, Ding Mingyan ${ }^{4}$, Luo Baochang ${ }^{5}$, Li \\ Qiong ${ }^{6}$ \\ ${ }^{1}$ Department of Endocrinology, ${ }^{2}$ Department of Orthopaedics, ${ }^{3}$ Department of Neurology, ${ }^{4}$ Department of Anesthesiology, \\ ${ }^{5}$ Department of Neurosurgery, ${ }^{6}$ Internal Medicine-Cardiovascular, Hanchuan People's Hospital, Hubei Province, Hanchuan City, \\ China
}

*For correspondence: Email: el1181@163.com

Sent for review: 19 October 2018

Revised accepted: 23 December 2018

\begin{abstract}
Purpose: To study the influence of sitagliptin on blood glucose, lipid and pancreatic $\beta$ cell function in type II diabetes mellitus (T2DM) patients.

Methods: Two groups of T2DM patients (100/group) received either metformin only (control group), or metformin plus sitaglipin (study group) for 3 months. Blood lipid profiles, fasting blood glucose (FBG), indices of pancreatic function and insulin resistance were assayed using standard biochemical methods. Results: The metformin-sitaglipin combination resulted in significant decreases in FBG, 2- $h$ PBG, $\mathrm{HbAlc}$ total cholesterol (TC), triacylglycerol, and low-density lipoprotein cholesterol (LDL-C), when compared with the metformin-only treatment $(p<0.05)$. Although there were significant decreases in pancreatic secretion of insulin, fasting insulin, and $2 \mathrm{~h}$ postprandial insulin in the two groups, these parameters were significantly lower in the metformin-only treated patients than in those with combination treatment $(p<0.05)$.

Conclusion: Sitagliptin normalizes fasting blood glucose, lipid profiles and insulin secretion in type II diabetes mellitus (T2DM) patients.
\end{abstract}

Keywords: Type 2 diabetes mellitus, Sitagliptin, Blood glucose, Pancreatic islet function, Insulin

\begin{abstract}
This is an Open Access article that uses a funding model which does not charge readers or their institutions for access and distributed under the terms of the Creative Commons Attribution License (http://creativecommons.org/licenses/by/4.0) and the Budapest Open Access Initiative (http://www.budapestopenaccessinitiative.org/read), which permit unrestricted use, distribution, and reproduction in any medium, provided the original work is properly credited.

Tropical Journal of Pharmaceutical Research is indexed by Science Citation Index (SciSearch), Scopus, International Pharmaceutical Abstract, Chemical Abstracts, Embase, Index Copernicus, EBSCO, African Index Medicus, JournalSeek, Journal Citation Reports/Science Edition, Directory of Open Access Journals (DOAJ), African Journal Online, Bioline International, Open-J-Gate and Pharmacy Abstracts
\end{abstract}

\section{INTRODUCTION}

Diabetes mellitus (DM) affects millions of people globally, with T2DM accounting for most of the reported cases of diabetes worldwide. It is known that T2DM is a primary DM caused by a combination of different factors such as insulin secretion deficiency and insulin resistance [1,2].
This disease is characterized by impaired function or failure of the pancreatic $\beta$ cells, and disorders in lipid and carbohydrate metabolism, often accompanied by abnormal increases in the levels of blood glucose and lipids.

In China, the incidence of DM is on the rise due to urbanization, and changing lifestyles especially changes in diet [3]. Although there are 
many treatment options for T2DM, they only serve as mere palliatives. As the disease progresses, hypoglycemia caused by excessive use of hypoglycemic drugs are common and pose threats to the safety of patients [4]. Hypoglycemic therapy alone cannot sufficiently protect the secretory function of pancreatic $\beta$ cells since this may decline with progression of the disease.

Sitagliptin inhibits the activity of dipeptidyl peptidase-4 (DDP-4) which controls the metabolism of hypoglycin-like peptide-1 (GLP-1) in diabetic patients. It has attracted huge attention as a new oral hypoglycemic drug [5]. Studies have suggested that DDP-4 inhibitors control the rate of degradation of GLP-1, delay its action time, promote the secretion of insulin, and accelerate the proliferation and recovery of the secretory function of pancreatic $\beta$ cells [6]. The present study was carried out to assess the clinical effect of sitagliptin on blood glucose, lipids and pancreatic $\beta$ cell function in T2DM subjects.

\section{METHODS}

\section{Materials}

Metformin was a product of Shanghai BristolMyers Squibb Pharmaceutical Co., Ltd., while sitagliptin was obtained from Merck Sharp and Dohme Italia SPA (Italy).

\section{Ethical approval}

The study received approval from the Ethical Committee of Hanchuan People's Hospital, Hubei Province (approval no. 20188180), and was conducted in line with the Helsinki Declaration of 1964 as amended in 1996 [7].

\section{General information on subjects}

Two groups of T2DM patients (200 subjects) were used in this study. The control comprised 63 males and 37 females with average age and mean disease duration of $53.5 \pm 11.6$ and3.2 \pm 1.4 years, respectively. The study group comprised 65 men and 35 women with average age and mean disease duration of $54.2 \pm 10.8$ and $3.2 \pm 1.6$ years, respectively. The demographic profile and disease duration in the two groups were comparable.

\section{Inclusion and exclusion criteria}

The patients selected were: (1) patients diagnosed with T2DM based on the Chinese Standards for the Prevention and Treatment of
T2DM (2013 edition); (2) patients of age $\geq 18$ years; (3) patients whose fasting blood glucose were between 6.5 and $14.3 \mathrm{mmol} / \mathrm{L} ;$ (4) patients with glycosylated hemoglobin between 6.5 and $11.0 \%$; (5) subjects with BMI $\geq 19 \mathrm{~kg} / \mathrm{m}^{2}$; (6) patients who had no disorders in heart, lung, liver and kidney function, as well as blood system disorders; and (7) patients who signed written informed consent with their family members. The exclusion criteria were: (1) patients who had major organ dysfunction, (cerebrovascular, liver, kidney, blood systems disorders and other serious diseases); (2) patients who were allergic to sitagliptin or metformin; (3) patients who had history of mental illness, and pregnant or lactating patients; (4) patients who were treated with other hypoglycemic drugs or insulin before the commencement of the study; and (5) patients who were on glucocorticoids.

\section{Treatment regimen}

\section{Control group}

Metformin was administered orally at an initial dose of $0.25 \mathrm{~g}$ per day with meals, and gradually increased to $2 \mathrm{~g}$ daily.

\section{Study group}

A combination of metformin and sitagliptin was administered, and the dose of metformin used was the same as that in controls. The oral dose of sitagliptin was $100 \mathrm{mg} / \mathrm{kg}$ b.wt./day. Treatment in the two groups lasted for 3 months, during which the patients paid close attention to their diets, carried out moderate exercise, and were not allowed to use other anti-diabetic drugs.

\section{Evaluation of treatment indices}

\section{Blood glucose and lipid levels}

Peripheral blood $(5 \mathrm{ml})$ was drawn from the veins of the patients pre- and post-treatment. Following centrifugation at $3000 \mathrm{rpm}$ for $10 \mathrm{~min}, 1 \mathrm{ml}$ of the resultant plasma was used within 30 min for determination of FBG and 2-h PBG using automated biochemical analyzer. Glycosylated hemoglobin $\mathrm{C}$ ( $\mathrm{HbAlc}$ ), TC, TG and LDL-C were determined using immuno-turbidimetric methods. Changes in FBG, 2-h PBG, HbAlc, TC, TG and LDL-C were measured pre- and post-treatment. The test kits were bought from Jianchen Biotechnology (Nanjing, China).

\section{Pancreatic $\beta$-cell function}

Plasma fasting insulin, 2-h PINS, HOMA- $\beta$ and HOMA-IR were measured. 


\section{Curative effect}

The curative effect was determined by following decreases in FBG and the improvements in clinical symptoms. Curative effect was classified into three: remarkably effective, effective and ineffective. The conditions applicable to each classification were: remarkably effective: clinical symptoms disappeared, FBG $<7.20 \mathrm{mmol} / \mathrm{L}, 2-\mathrm{h}$ $\mathrm{PBG}<8.27 \mathrm{mmol} / \mathrm{L}$, and HbAlc $<7.0 \%$; effective: obvious improvements in clinical symptoms, with FBG $<8.30 \mathrm{mmol} / \mathrm{L}$, 2-h PBG < $10.0 \mathrm{mmol} / \mathrm{L}$, and $\mathrm{HbAlc}<7.5 \%$; ineffective: no improvements in clinical symptoms, and no appreciable decreases in blood glucose levels. The total effectiveness was calculated as in Eq 1.

$\operatorname{TE}(\%)=R e+E$

where $T E$ is total effectiveness, $R e$ is remarkably effective, and $E$ is effective.

\section{Safety}

Adverse reactions such as gastrointestinal reaction, duration of hypoglycemia and abnormal liver and kidney functions were recorded.

\section{Statistical analysis}

The results are expressed as mean \pm SEM, and were statistically analyzed using SPSS (18.0). comparison between groups was carried out with Student $t$ - and Chi-squared tests. Statistical significance was assumed at $p<0.05$.

\section{RESULTS}

\section{Blood glucose}

The levels of FBG, 2-h PBG and HbAlc were significantly reduced in both groups of patients after treatment $(p<0.05)$. As shown in Table 1, the combined treatment with metformin and sitagliptin resulted in significant decreases in 2-h PBG, FBG, relative to treatment with metformin only $(p<0.05)$.

Table 1: Levels of FBG, 2-h PBG and HbAlc in the two groups $(n=100)$

\begin{tabular}{llccc}
\hline Group & $\begin{array}{l}\text { Time } \\
\text { point }\end{array}$ & $\begin{array}{c}\text { FBG } \\
\text { (mmol/L) }\end{array}$ & $\begin{array}{c}\text { 2h PBG } \\
\text { (mmol/L) }\end{array}$ & $\begin{array}{c}\text { HbAlc } \\
\text { (\%) }\end{array}$ \\
\hline \multirow{4}{*}{ Study } & Before & $9.55 \pm$ & $14.11 \pm$ & $9.43 \pm$ \\
& treatment & 2.42 & 3.28 & 2.21 \\
& After & $6.55 \pm$ & $8.53 \pm$ & $7.11 \pm$ \\
& treatment & $2.11^{\star \#}$ & $2.86^{\star \#}$ & $1.84^{\star \#}$ \\
& Before & $9.56 \pm$ & $13.88 \pm$ & $9.46 \pm$ \\
Control & treatment & 2.34 & 2.56 & 2.45 \\
& After & $7.78 \pm$ & $10.93 \pm$ & $8.22 \pm$ \\
& treatment & $1.95^{\star}$ & $2.77^{\star}$ & $1.45^{\star}$ \\
\hline
\end{tabular}

${ }^{*} P<0.05$, relative to pre-treatment value; ${ }^{\#} p<0.05$, relative to control group

\section{Blood lipid levels}

Table 2 shows that there were significant reductions in post-treatment levels of TC, TG and LDL-C in the two groups $(p<0.05)$. Their levels in the observation group were significantly lower than those in the control group $(p<0.05)$. These results are shown in Table 2.

\section{Pancreatic $\beta$ cell function}

Table 3 shows that after treatment, there were significant increases in FINS, 2-h PINS and HOMA- $\beta$, and marked decreases in HOMA-IR in the two groups $(p<0.05)$. The combination treatment with metformin and sitagliptin led to significant increases in FINS, 2-h PINS and HOMA- $\beta$, when compared with patients treated with metformin alone, but HOMA-IR was significantly higher in the control group ( $p<$ 0.05).

Table 2: Blood lipid levels in both groups $(n=100)$

\begin{tabular}{lcccc}
\hline Group & Time point & TC $(\mathbf{m m o l} / \mathbf{L})$ & TG $(\mathbf{m m o l} / \mathbf{L})$ & LDL-C $(\mathbf{m m o l} / \mathbf{L})$ \\
\hline \multirow{2}{*}{ Study } & Pre-treatment & $5.55 \pm 0.82$ & $2.41 \pm 0.26$ & $3.13 \pm 0.21$ \\
& Post-treatment & $4.23 \pm 0.71^{\text {*\# }}$ & $1.51 \pm 0.23^{\text {*\# }}$ & $2.21 \pm 0.24^{\star *}$ \\
Control & Pre-treatment & $5.56 \pm 0.74$ & $2.38 \pm 0.28$ & $3.16 \pm 0.25$ \\
& Post-treatment & $4.88 \pm 0.75^{\star}$ & $1.84 \pm 0.27^{\star}$ & $2.62 \pm 0.27^{*}$ \\
\hline
\end{tabular}

${ }^{*} P<0.05$, relative to pre-treatment value; ${ }^{\#} p<0.05$, relative to control group

Table 3: Pancreatic $\beta$ cell function ( $N=100)$

\begin{tabular}{lccccc}
\hline Group & Time point & FINS (mU/L) & PINS (mU/L) & HOMA-IR & HOMA- $\boldsymbol{\beta}$ \\
\hline \multirow{2}{*}{ Study } & Before treatment & $7.24 \pm 1.21$ & $44.11 \pm 6.24$ & $3.64 \pm 0.84$ & $31.17 \pm 14.27$ \\
& After treatment & $11.56 \pm 1.61^{\star \#}$ & $58.53 \pm 7.26^{\text {*\# }}$ & $2.91 \pm 0.54^{\text {*\# }}$ & $62.03 \pm 17.21^{\text {*\# }}$ \\
& Before treatment & $7.22 \pm 1.34$ & $43.88 \pm 7.54$ & $3.62 \pm 0.81$ & $31.21 \pm 16.34$ \\
Control & After treatment & $8.78 \pm 1.35^{\star}$ & $49.93 \pm 7.68^{\star}$ & $3.22 \pm 0.63^{*}$ & $39.93 \pm 15.54^{*}$ \\
\hline
\end{tabular}

${ }^{\star} P<0.05$, relative to pre-treatment value; ${ }^{\#} p<0.05$, relative to control group 
Table 4: Clinical effectiveness of sitagliptin (N, \%)

\begin{tabular}{lccccc}
\hline Group & $\mathbf{n}$ & Remarkably effective & Effective & Ineffective & Total effectiveness \\
\hline Study & 100 & $69(69.0 \%)$ & $20(20.0 \%)$ & $11(11.0 \%)$ & $89.0 \%$ \\
Control & 100 & $49(49.0 \%)$ & $24(24.0 \%)$ & $27(27.0 \%)$ & $73.0 \%$ \\
$X^{2}$ & - & 8.267 & 0.466 & 8.317 & 8.317 \\
$P$ & - & 0.004 & 0.495 & 0.004 & 0.004 \\
\hline
\end{tabular}

\section{Curative effect}

As shown in Table 4, after treatment, the proportion of remarkable effects was markedly higher in the combination treatment group, when compared to metformin-only group $\left(x^{2}=8.267, p\right.$ $<0.05)$. Effectiveness in the two groups were comparable $\left(x^{2}=0.466, p>0.05\right)$. However, total effectiveness in the combination treatment (89 $\%$ ) was superior to that of the metformin-only group $(73.0 \%) \quad\left(x^{2}=8.317, p<0.05\right)$. Ineffectiveness in the study group was significantly lower than in the control group $\left(x^{2}=\right.$ 8.317, $p<0.05)$.

\section{Outcome of safety assessment}

There were adverse reactions (gastrointestinal reactions) in both groups. However, there were no abnormal liver and kidney functions, and no severe hypoglycemia. Adverse reactions were similar in the two groups $(p>0.05)$.

\section{DISCUSSION}

Diabetes mellitus is characterized either by insulin insufficiency or inability to effectively utilize insulin [8]. This disease is characterized by abnormal elevation of blood glucose. Prolonged hyperglycemia damages blood vessels, nerves and other tissues, causing irreversible complications that can adversely affect human health [9]. Type 2 DM, also known as adult onset diabetes, is caused by insulin insufficiency or ineffective use of insulin, and it accounts for more than $90 \%$ of total reported cases of DM. More than half of patients with T2DM have loss of pancreatic $\beta$ cell function at the first visit, and if not properly treated, total pancreatic failure may occur as the disease progresses. At present, DPP-4 inhibitors have attracted huge attention as new drugs for the treatment of T2DM [10,11]. The results obtained in this study suggest that sitagliptin effectively reduces FBG and blood lipid profiles.

The proportion of remarkable effects was markedly higher in the combination treatment group, when compared to metformin-only group. Effectiveness in the two groups were comparable. However, total effectiveness in the combination treatment was superior to that of the metformin-only group. Thus, sitagliptin reduces the clinical symptoms of T2DM. Although the hypoglycemic effect of sitagliptin is widely recognized, its hypolipidemic effect has not been thoroughly studied. Previous studies have shown that sitagliptin, as an inhibitor of DPP-4 does not directly participate in the metabolism of blood lipids, but it can indirectly reduce blood lipids by acting on sympathetic reflex and enhancing postprandial lipid mobilization and degradation [12]. Some studies have also suggested that sitagliptin increases blood level of GLP-1 which acts on the hypothalamus, and decreases appetite, calorie and fat ingestion by reducing gastric emptying time and increasing satiety [13]. Sitagliptin effectively improves pancreatic islet function by inhibiting the decomposition of endogenous incretin GLP-1 while increasing the concentration and duration of its action. This promotes the secretion of insulin while inhibiting the secretion of glucagon, thereby lowering blood glucose. Moreover, GLP-1 enhances differentiation and proliferation of pancreatic $\beta$ cells by inhibiting their apoptosis. Therefore, sitagliptin can indirectly increase pancreatic $\beta$ cell population and slow down failure in their function [14].

\section{Limitation of the study}

This research only evaluated the effect of sitagliptin on T2DM after treatment, without evaluating the effectiveness of continuous sitagliptin use.

\section{CONCLUSION}

The results obtained in this study have shown that sitagliptin improves blood glucose and lipid levels, as well as pancreatic $\beta$ cell function in type II diabetes mellitus (T2DM) patients. Therefore, it is effective in the treatment of T2DM.

\section{DECLARATIONS}

\section{Conflict of Interest}

No conflict of interest associated with this work. 


\section{Contribution of Authors}

We declare that this work was done by the author(s) named in this article and all liabilities pertaining to claims relating to the content of this article will be borne by the authors. All authors read and approved the manuscript for publication. Song Wenrong conceived and designed the study; Song Wenrong, Zhang Lei, Pan Zaoxia, Ding Mingyan, Luo Baochang, Li Qiong collected and analysed the data, while $\mathrm{Li}$ Qiong wrote the manuscript.

\section{REFERENCES}

1. Zhao S, Shi YS, Endocrinology DO. Comparison of clinical efficacy of Liraglutide and Insulin pump in newly diagnosed obese patients with type 2 diabetes mellitus. China Mod Med 2018; (5): 44-46.

2. Li LJ, LiU GP, Yu L. Research progress in the treatment of type 2 diabetes mellitus with SGLT2 inhibitors. Chin J Integr Tradit West Nephrol 2016; 17(1): 82-85.

3. Wen JP, Tian YP. Research Progress of screening for High risk population of Type 2 Diabetes Mellitus. Int $J$ Lab Med 2015; (18): 2711-2713.

4. Li FN, Chen Y, Kuang P, Liu KF. Clinical comparative study of two oral hypoglycemic drugs combined with insulin against firstly diagnosed T2DM. Chin J Hosp Pharm 2017; 37(3): 270-272

5. Thomas MC, Paldánius PM, Ayyagari R, Ong SH, Groop PH. Systematic Literature Review of DPP-4 Inhibitors in Patients with Type 2 Diabetes Mellitus and Renal Impairment. Diabetes Ther 2016; 7(3): 1-16.
6. Li R, Wang R, Li H, Sun S, Zou M, Cheng G. Short-term and long-term effects of dipeptidyl peptidase-4 inhibitors in type 2 diabetes mellitus patients with renal impairment: a meta-analysis of randomized controlled trials. Diabetes Metab Res Rev 2016; 32(6): 460-469.

7. World Health Organization. Declaration of Helsinki. $\mathrm{Br}$ Med J 1996; 313(7070): 1448-1449.

8. Zhou CL, Qiu X, He X. Effect observation of basal insulin combined with oral antidiabetic drugs in treating type 2 diabetes mellitus. Int J Lab Med 2015; (7): 956-958.

9. Dai B, Wu Q, Zeng C, Zhang J, Cao L, Xiao Z, Yang M. The effect of Liuwei Dihuang decoction on PIJK/Akt signaling pathway in liver of type 2 diabetes mellitus (T2DM) rats with insulin resistance. J Ethnopharmacol 2016; 192: 382-389.

10. Kim YG, Byun JH, Yoon D, Jeon JY, Han SJ, Kim JD, Lee KW, Park RW, Kim JH. Renal Protective Effect of DPP-4 Inhibitors in Type 2 Diabetes Mellitus Patients: $A$ Cohort Study. J Diabetes Res 2016; 2016(6): 1-9.

11. Jamaluddin JL, Huri HZ, Vethakkan SR. Clinical and genetic predictors of dipeptidyl peptidase-4 inhibitor treatment response in Type 2 diabetes mellitus. Pharmacogenomics 2016; 17(8): 867.

12. Kusunoki M, Sato D, Nakamura $T$, Oshida $Y$, Tsutsui $H$, Natsume Y, Tsutsumi K, Miyata T. The Beneficial Effects of the DPP-4 Inhibitor Alogliptin on Hemoglobin A1c and Serum Lipids in Japanese Patients with Type 2 Diabetes. Drug Res 2016; 66(1): 18.

13. Liu ZJ, Dai CG. Efficacy of liraglutide GLP-1 analogues combined with DPP-4 inhibitor in obese patients with type 2 diabetes. Jilin Med J 2016; 3(2): 327-329.

14. Yu M. Dipeptidyl peptidase IV inhibitor: multiple benefits beyond the hypoglycemic effect. Chin J Diabetes Mellit 2017; 9 (4): 270-272. 